AGREGAT: Jurnal Ekonomi dan Bisnis

Vol. 2, No. 2, September 2018

http://journal.uhamka.ac.id/index.php/agregat

p-ISSN: 2580-3360 e-ISSN: 2581-2874

DOI: $10.22236 /$ agregat_vol1/is4pp377-387

Hal 377-387

\title{
KOMPONEN INFORMASI DAN KOMUNIKASI \\ SERTA PEMANTAUAN ATAS SIKLUS PENGELUARAN
}

\author{
Hera Khairunnisa \\ Universitas Muhammadiyah Prof. DR. HAMKA \\ Email: hera.uhamka@gmail.com
}

Diterima: 3 Juni 2018; Direvisi: 7 Juni 2018; Disetujui: 25 Juni 2018

\begin{abstract}
This research aims to analyze and give suggestion on internal control system in expenditure cycle of Unit A by comparing components on the Committee of Sponsoring Organizations of the Treadway Commission (COSO) internal control framework that consisted of environment control, risk assessment, control activity, information and communication, and monitoring. The method of analysis data is using qualitative analysis by gathering data with interview, document review, and literature review. Conclusion from information and communication component is that the entity does not have standard information on the completeness of supporting data for cash disbursement transactions. Conclusion of monitoring is that the logistic manager has not conducted optimal monitoring of the process of receiving goods in the warehouse.
\end{abstract}

Keywords: Information and communication, monitoring, expenditure cycle, COSO, Unit A.

\begin{abstract}
Abstrak
Penelitian ini bertujuan untuk menganalisis dan memberi usulan pada sistem pengendalian internal siklus pengeluaran kas Unit A dengan membandingkan komponen-komponen dalam kerangka pengendalian internal dari Committee of Sponsoring Organizations of the Treadway Commission (COSO) yang terdiri dari lingkungan pengendalian, penilaian risiko, aktivitas pengendalian, informasi dan komunikasi, dan pemantauan. Metode analisis data menggunakan analisis kualitatif dengan mengumpulkan data yang bersumber dari wawancara, telaah dokumen, dan tinjauan pustaka.Kesimpulan penelitian atas penelaahan komponen informasi dan komunikasi yaitu entitas belum memiliki standar informasi atas kelengkapan data pendukung transaksi pengeluaran kas. Kesimpulan atas pemantauan yaitu manajer logistik belum melakukan pemantauan optimal atas proses penerimaan barang di gudang.
\end{abstract}

Kata kunci: Informasi dan komunikasi, pemantauan, siklus pengeluaran kas, COSO, Unit A. 


\section{PENDAHULUAN}

Kecurangan merupakan tindakan yang dilakukan secara sengaja oleh seseorang yang dapat mengakibatkan kesalahan material pada penyajian laporan keuangan suatu perusahaan (Astuti, Zuhrotun, dan Kusharyanti, 2015).Pada umumnya, kecurangan terbagi menjadi tiga bentuk yaitu penyalahgunaan aset, kecurangan laporan keuangan, dan korupsi (Astuti, Zuhrotun, dan Kusharyanti).Kecurangan yang dilakukan oleh oknum-oknum tertentu berdampak negatif pada eksistensi perusahaan tersebut.Enron merupakan salah satu perusahaan yang runtuh akibat adanya kecurangan yang dilakukan oleh oknum perusahaan.

Enron merupakan perusahaan penyedia energi terbesar didunia pada era 2000-an (Astuti, Zuhrotun, dan Kusharyanti, 2015).Enron melakukan tindak kecurangan dengan melaporakan sejumlah pendapatan di laporan keuangannya sementara fakta yang ada justru membuktikan perusahaan tersebut mengalami kerugian (Ghozali dan Achmad, 2018).Adanya kecurangan tersebut membuat Enron mengalami keterpurukan dan akhirnya mengalami kebangkrutan.Runtuhnya Enron tersebut mengakibatkan kerugian \$70 Miliar di pasar modal (Huang et al., 2016). Di Indonesia juga terdapat beberapa perusahaan yang melakukan tindak kecurangan dalam kegiatan usahanya.Kecurangan atas pelaporan keuangan di Indonesia dilakukan oleh PT Kimia Farma, PT Pakuwon Jati, PT Energi Mega Persada, PT Waskita Karya, dan sebagainya (Astuti, Zuhrotun, dan Kusharyanti, 2015). PT Kimia Farma memanipulasi angka di laporan keuangannya (Ghozali dan Achmad, 2018).Kecurangan tersebut membuat pengguna laporan keuangan dibohongi karena angka laporan keuangan yang tertera dalam laporan keuangan tersebut merupakan hasil rekayasa dari manajamen.Rekayasa atas informasi di dalam laporan keuangan memicu kesalahan pada pengambilan keputusan yang dilakukan oleh pengguna laporan keuangan.

Kasus kecurangan yang terjadi pada Enron membuktikan bahwa perusahaan tersebut kurang menerapkan nilai etika dalam praktik bisnisnya (Said, et al., 2017).Penerapan nilai etika merupakan bagian penting dari penerapan sistem pengendalian internal perusahaan.Lokanan (2014) juga menyatakan bahwa kecurangan pada pelaporan keuangan yang dilakukan oleh perusahaan disebabkan oleh belum optimalnya penerapan pengendalian internal di perusahaan tersebut. Pengendalian internal menurut Romney dan Steinbart (2015) yaitu suatu sistem yang berkaitan dengan prosedur dan praktik yang dikembangkan oleh entitas yang bertujuan untuk mengamankan aset, memastikan 
379 AGREGAT: Jurnal Ekonomi dan Bisnis

Vol. 2, No. 2, September 2018

http://journal.uhamka.ac.id/index.php/agregat

p-ISSN: 2580-3360 e-ISSN: 2581-2874

DOI: 10.22236/agregat_vol1/is4pp377-387

Hal 377-387

keakuratan informasi akuntansi,

meningkatkan efisiensi, dan mengukur

kepatuhan manajemen pada kebijakan dan

prosedur. Pengendalian internal tidak hanya diterapkan pada entitas berskala bisnis besar, namun dapat diterapkan pula pada entitas berskala kecil. Penerapan sistem pengendalian internal berbeda antara satu entitas dengan entitas lain tergantung dari berbagai faktor (Giriunas, 2009).

Mutu dari pengendalian internal dapat dinilai dari penelaahan desain dan implementasinya melalui kerangka pengendalian yang ada (Committee of Sponsoring Organizations of the Treadway Commission, 2013). Pengendalian internal yang didefinisikan oleh Committee of Sponsoring Organizations of the Treadway Commissions memiliki arti yaitu suatu proses yang dipengaruhi oleh peran direksi, manajemen, dan karyawan yang dirancang untuk memberikan keyakinan yang memadai terkait dengan pencapaian tiga aspek tujuan yaitu operasional, pelaporan, serta kepatuhan. Keefektivan sistem pengendalian internal dapat dinilai dari implementasi kelima komponen kerangka pengendalian internal dari Committee of Sponsoring Organizations of The Treadway Commission (COSO) (Lansiluoto, Jokipii, dan Eklund, 2016). Komponen pengendalian internal yang disusun oleh
Committee of Sponsoring Organizations of the Treadway Commission pada 2013 terdiri dari lingkungan pengendalian, penilaian risiko, aktivitas pengendalian, informasi dan komunikasi, serta kegiatan pemantauan.Awalnya, penelitian ini dilakukan dengan wawancara pendahuluan dengan objek penelitian untuk mengetahui permasalahan penelitian. Wawancara pendahuluan tersebut melibatkan Satuan Pengawasan Internal (SPI) Yayasan X. Selain wawancara pendahuluan, peneliti juga melakukan penelaahan Laporan Hasil Pemeriksaan (LHP) tahun 2016 yang dihasilkan SPI untuk memahami lebih mendalam mengenai permasalahan pada objek penelitian.

Yayasan X merupakan entitas berbadan hukum yang kegiatan utamanya adalah memberikan jasa pengajaran di bidang bahasa baik formal maupun nonformal.Sampai dengan saat ini, Yayasan $\mathrm{X}$ telah memiliki enam unit kegiatan.Unit $\mathrm{A}$ merupakan unit kegiatan terbesar yang dimiliki Yayasan X. Unit A merupakan lembaga pendidikan bahasa asing non formal yang memiliki banyak cabang di Indonesia.Unit A memiliki dua puluh kantor cabang dan lima puluh kantor kerjasama yang tersebar di seluruh Indonesia. Unit A membuka program pengajaran bahasa asing empat kali dalam satu tahun.Term 
1/Triwulan I diselenggarakan dari JanuariMaret, Term 2/Triwulan 2 diselenggarakan pada April-Juni.Term 3/Triwulan 3 diselenggarakan pada Juli-September dan Term 4/Triwulan 4 diselenggarakan pada Oktober-Desember. Jenis program kelas dibagi menjadi dua yaitu program kelas umum dan kelas luar.Atas penelaahan LHP Kantor Pusat Unit A periode November 2014 sampai September 2016, penelitian ini melihat adanya temuan-temuan pada siklus pengeluaran.Temuan tersebut disebabkan adanya ketidaksesuaian antara pelaksanaan dengan desain sistem pengendalian internal/Standar Operasional Prosedur (SOP) yang ditetapkan. Selain itu terdapat temuan atas penumpukan buku pembelajaran yang telah dibeli oleh Unit A. Kantor Pusat Unit A berfungsi sebagai cost center dengan fungsi melakukan pengeluaran atas pembelian yang bersifat terpusat untuk seluruh cabang-cabangnya.

LHP juga nenjelskan adanya beberapa transaksi pengeluaran yang tidak dilengkapi dengan bukti pendukung yang memadai seperti tagihan/invoice asli dari pemasok. Terdapat pula beberapa transaksi pengeluaran yang tidak didukung oleh otorisasi pejabat berwenang pada dokumen pendukung.Terdapat dokumen pendukung transaksi pengeluaran yang tidak merepresentasikan jumlah/saldo transaksi
tersebut.Temuan lainnya menunjukkan adanya transaksi pengeluaran yang tidak dicatat pada akun yang tepat (Yayasan X, 2016). Penumpukan buku tidak hanya terdapat di gudang Yayasan $\mathrm{X}$, tetapi terdapat pula di gudang pemasok buku.Penumpukan buku di gudang pemasok telah terjadi dari 2014 dan sampai saat ini belum ada tindakan Unit A untuk mengatasi hal tersebut (Yayasan X, 2016).Penumpukan buku di gudang milik Yayasan $\mathrm{X}$ terjadi sekitar tahun 2014.Penumpukan buku tersebut terjadi atas kontrak dengan distributor buku periode 2013-2017. Penumpukan buku di gudang Yayasan X tentu menimbulkan risiko penambahan carrying cost dan biaya pemeliharaan bagi Unit A.

Temuan SPI terkait dengan ketidaklengkapan dokumen pendukung proses pengeluaran menunjukkan adanya risiko atas pembelian fiktif atau pembayaran berulang ke pemasok (Romney dan Steinbart, 2015). Atas penelaahan SOP keuangan dan akuntansi Yayasan $\mathrm{X}$ tidak terdapat pernyataan yang menjelaskan mengenai kriteria kelengkapan dokumen pendukung yang harus dipenuhi.Temuan tersebut dapat terjadi karena ketidakpahaman pelaksana pengendalian internal terhadap pentingnya prosedur yang ada atau kurangnya informasi atas pelaksanaan 
381 AGREGAT: Jurnal Ekonomi dan Bisnis

Vol. 2, No. 2, September 2018

http://journal.uhamka.ac.id/index.php/agregat

p-ISSN: 2580-3360 e-ISSN: 2581-2874

DOI: 10.22236/agregat_vol1/is4pp377-387

Hal 377-387

prosedur tersebut. Dari penjelasan tersebut di atas, maka peneliti tertarik untuk melakukan penelitian pada sistem pengendalian pada Unit $\mathrm{A}$ atas siklus pengeluaran. Tujuan dari penelitian ini adalah untuk menganalisis kondisi pengendalian internal pada sistem pengeluaran Unit A serta menyarankan perbaikan yang dibutuhkan oleh Unit A. Siklus pengeluaran merupakan suatu siklus atau proses yang terdiri dari proses pembelian dan pengeluaran kas (Romney dan Steinbart, 2015).

Penelitian ini meneliti sistem pengendalian internal dengan menggunakan instrumen komponen pengendalian Internal dari Committee of Sponsoring Organizations of The Treadway Commission. Sistem pengendalian yang dibahas pada penelitian dibatasai hanya pada komponen informasi dan komunikasi serta komponen pemantauan.Pembatasan tersebut dilakukan karena pemantauan merupakan aspek yang harus dilakukan untuk memastikan sistem pengendalian internal telah dilaksanakan sesuai prosedur.

\section{METODE PENELITIAN}

Jenis penelititan ini adalah penelitian kualitatif dengan menggunakan pendekatan studi kasus. Dalam Wahyuni (2012), metode penelitian kualitatif merupakan pendekatan induktif yang bertujuan untuk mendapatkan pemahaman lebih mendalam atas kelompok/orang tertentu. Penelitian kualitatif menempatkan objek penelitian sebagai suatu interpretasi atas gejala yang diamati, sesuatu yang dinamis, serta hasil konstruksi pemikiran yang bersifat utuh/holistik.Hal tersebut disebabkan karena setiap aspek dari objek penelitian memiliki satu kesatuan yang tidak terpisahkan (Sugiyono, 2011). Menurut Yi (1984) dalam Wahyuni (2012) penelitian studi kasus adalah penyelidikan empiris untuk menyelidiki fenomena kontemporer di konteks kehidupan nyata.Batasan antara fenomena dengan teori tidak dapat dibedakan/tidak terlihat secara jelas.Dalam jenis penelitian ini, studi kasus juga merupakan penelitian yang menyelidiki kasus dari berbagai macam bukti dan sumber yang dipergunakan.Penelitian ini menggunakan pendekatan studi kasus dengan objek penelitian yaitu Kantor Pusat Unit A.

Penelitian ini menggunakan data primer yang didapatkan melalui wawancara langsung dengan unit-unit analisis.Selain itu data primer dalam penelitian ini juga didapatkan melalui melalui observasi atas kegiatan-kegiatan di unit analisis tersebut.Dalam penelitian ini digunakan juga data sekunder yang didapatkan melalui analisis dan penelaahan dari dokumen-dokumen 
yang dihasilkan oleh Unit A. Data-data tersebut antara lain Kebijakan dan SOP Keuangan dan Akuntansi Umum, Kebijakan dan SOP Pengadaan Barang dan Jasa, struktur organisasi entitas, daftar pekerjaan dan tanggung jawab Manajer Departemen Logistik, dan buku core values Yayasan X. Selain itu data sekunder juga didapat melalui LHP SPI periode 2014-2016, Rencana Strategis Yayasan X, Rencana Kerja Anggaran Departemen Logistik 2017, dan dokumendokumen terkait dengan siklus pengeluran kas.Sistem pengendalian internal dalam penelitian ini dibatasi pada dua komponen kerangka pengendalian internal dari Committee of Sponsoring Organizations of the Treadway Commission yaitu informasi dan komunikasi serta pemantauan.

Kedua komponen tersebut masingmasing memiliki butir-butir prinsip pendendalian internal. Komponen informasi dan komunikasi terdiri dari prinsip; penggunaan informasi yang relevan dan berkualitas;optimalisasi proses komunikasi internal; optimalisasi proses komunikasi eksternal. Sementara komponen pamantauan terdiri dari prinsip: pemilihan, pengembangangan, dan pengevaluasian berkelanjutan atas pengendalian internal; pengevaluasian dan penyampaian kelemahan pengendalian internal secara tepat waktu kepada pihak yang bertanggung jawab atas pengendalian internal tertentu.

\section{HASIL DAN PEMBAHASAN}

Penelitian ini bertujuan untuk menganalisis sistem pengendalian internal pada siklus pengeluaran Unit A dan memberikan masukan atau usulan perbaikan pada sistem pengendalian internal Unit A. Tahapan yang ada dalam penelitian ini adalah tahap wawancara pendahuluan yaitu merupakan tahap pertama yang dilakukan untuk menemukan permasalahan pada objek penelitian.Peneliti melakukan wawancara pendahuluan dengan SPI Yayasan X dan menyimpulkan bahwa terdapat masalah pada sistem pengeluaran Unit A.

Setelah itu, peneliti melakukan tahap kedua yaitu tahap analisis current situation pengendalian internal Unit A dengan menggunakan data primer dan data sekunder.Pada tahap kedua, peneliti menganalisis current situation atas siklus pengeluaran kas berdasarkan komponen kerangka pengendalian internal dari Committee of Sponsoring Organizations of The Treadway Commission.Pada tahap ketiga, peneliti memberikan usulan perbaikan atas current situation pada Unit A yang belum sesuai dengan kaidah pengendalian internal dari Committee of Sponsoring Organizations of The Treadway Commission. 
383 AGREGAT: Jurnal Ekonomi dan Bisnis

Vol. 2, No. 2, September 2018

http://journal.uhamka.ac.id/index.php/agregat

p-ISSN: 2580-3360 e-ISSN: 2581-2874

DOI: 10.22236/agregat_vol1/is4pp377-387

Hal 377-387

Pada bagian ini, peneliti menjelaskan mengenai tahap analisis current situation dan tahap pemberian usulan perbaikan bagi Unit A. Peneliti menganalisis masingmasing prinsip yang terdapat pada komponen informasi dan komunikasi yaitu: penggunaan informasi yang relevan dan berkualitas; optimalisasi proses komunikasi internal; optimalisasi proses komunikasi eksternal.Siklus pengeluaran Unit A yaitu terdiri dari; proses pengajuan permintaan dan pembelian dari masing-masing kantor cabang/departemen di Unit A kepada Departemen Logistik Unit A; proses penerimaan barang yang telah dipesan; proses pemrosesan tagihan dari pemasok; proses pembayaran ke pemasok.

Contoh dari siklus pengeluaran Unit A adalah proses pengadaan buku pembelajaran Unit A, pengadaan jasa perbaikan, dan sebagainya. Peneliti melakukan penelaahan dokumen yaitu hasil pemeriksaan/ LHP dari SPI.Hasil pemeriksaan SPI menunjukkan pada Januari 2015 terdapat dua transaksi pembelian tidak didukung oleh tagihan/invocie asli.Peneliti juga menemukan terdapat sembilan transaksi pengeluaran yang tidak didukung oleh tagihan asli pada Februari dan Oktober 2015. Setelah itu peneliti melakukan wawancara dengan SPI terkait dengan temuan tersebut.SPI

menjelaskan bahwa adanya temuan tersebut dipicu karena adanya kelalaian dari karyawan yang bertanggung jawab atas pengendalian internal tersebut.Peneliti juga melakukan wawancara dengan karyawan departemen akuntansi dan logistik.Hasil wawancara menunjukkan bahwa karyawan tidak mengetahui dengan jelas kriteria dokumen yang dianggap lengkap sesuai dengan kaidah pengendalian internal dan SOP yang ada.Tidak hanya terbatas pada pemeriksaan dari SPI saja, peneliti juga melakukan pemeriksaan sendiri terkait dengan dokumen siklus pengeluaran Unit A periode Januari 2017.Peneliti menemukan tiga transaksi pengeluaran di bulan Januari 2017 yang tidak disertai bukti penerimaan barang dan tiga transaksi yang tidak disertakan tagihan asli dari pemasok.

Peneliti melakukan konfirmasi dengan staf departemen akuntansi dan logistik. Ketidaklengkapan bukti pendukung transaksi pengeluaran dikarenakan staf tidak mengetahui informasi yang jelas terkait dengan kriteria kelengkapan dokumen yang dibutuhkan dalam memproses transaksi pengeluaran. Berdasarkan wawancara dengan staf akuntansi dan logistik adanya ketidaklengkapan dokumen dapat diterima asalkan wakil direktur keuangan atau manajer akuntansi telah menyetujui adanya 
pengeluaran dana. Informasi yang tidak relevan untuk mendukung siklus pengeluaran Unit A akan berisiko pada Unit A. Jika staf akuntansi tidak mengetahui informasi terkait kelengkapan dokumen yang penting bagi siklus pengeluaran, maka risiko yang mungkin muncul adalah pembayaran pada pemasok atas barang yang tidak diterima (Romney dan Steinbart, 2015). Selain itu, risiko yang mungkin muncul adalah adanya pembelian fiktif serta pembayaran ganda pada suatu tagihan dari pemasok. Jika hal tersebut terus dibiarkan maka entitas akan mengganggu aspek efisiensi perusahaan (Romney dan Steinbart, 2015).

Untuk menanggapi hal tersebut penelitian ini mengusulkan adanya informasi formal dan jelas mengenai syarat kelengkapan dokumen yang menjadi dasar memadai suatu

transaksi pengeluaran.Peneliti menyarankan agar department Unit A membuat suatu formulir yang berisikan daftar-daftar kelengkapan dokumen yang dibutuhkan dalam pengeluaran kas. Pihak yang mengajukan permintaan dana harus melengkapi dokumen yang tertera di formulir tersebut, setelah itu staf akuntansi akan dapat pemroses pengeluaran kas berdasarkan dokumen pendukung yang emmadai. Tagihan asli merupakan dasar untuk melakukan pembayaran ke pemasok (Romney dan Steinbart, 2015).Secara umum prinsip optimalisasi proses komunikasi internal sudah dipenuhi oleh Unit A. Unit A telah memiliki jalur komunikasi internal yang memadai. Hal tersebut didukung dengan adalah memorandum, e-mail, pesan elektronik per departemen, dan surat-surat formal lainnya. Terdapat pula rapat rutin per tiga bulan direksi dengan kantor cabang per regional. Terdapat pula rapat rutin Wakil Direktur Keuangan dengan manajer-manajer. Secara umum prinsip optimalisasi proses komunikasi eskternal sudah dipenuhi oleh Unit A. Jalur komunikasi dengan pihak eksternal dilaksanakan melalui telepon, e-mail, surat resmi atau pesan elektronik lainnya. Penelitian terdahulu dilakukan oleh Maguire pada tahun 2014 pada sistem pengendalian internal di organisasi non-profit.

Maguire (2014) menyatakan bahwa komponen informasi memegang peranan penting dalam implementasi sistem pengendalian internal. Perusahaan harus dapat memastikan bahwa informasi penting terkait pengendalian internal disampaikan ke pihakpihak yang berkepentingan dengan cara komunikasi yang efektif. Perusahaan harus menerapkan kebijakan yang tegas dan jelas agar pengendalian internal dapat berjalan dengan baik (Maguire, 2014).Pada bagian ini, peneliti menjelaskan mengenai tahap an- 
385 AGREGAT: Jurnal Ekonomi dan Bisnis

Vol. 2, No. 2, September 2018

http://journal.uhamka.ac.id/index.php/agregat

p-ISSN: 2580-3360 e-ISSN: 2581-2874

DOI: 10.22236/agregat_vol1/is4pp377-387

Hal 377-387

alisis current situation dan tahap pemberian usulan perbaikan bagi Unit A. Peneliti menganalisis masing-masing prinsip yang terdapat pada komponen pemantauan yaitu; pemilihan, pengembangangan, dan pengevaluasian berkelanjutan atas pengendalian internal; pengevaluasian dan penyampaian kelemahan pengendalian internal secara tepat waktu kepada pihak yang bertanggung jawab atas pengendalian internal tertentu.Analisis prinsip pertama pada komponen pemantauan menunjukkan evaluasi berjalan yang dilaksanakan Unit A adalah melalui evaluasi anggaran yang dilaksanakan oleh Manajer Keuangan dan Akuntansi. Pada umumnya jika terdapat pembelian atas barang/jasa yang tidak dianggarkan, manajemen akan mempertimbangkan tingkan kebutuhan dari barang tersebut. Sehingga biasanya walaupun tidak dianggarkan, barang tersebut dapat dapat dibeli karena mendesaknya kebutuhan akan barang tersebut. Bentuk pemantauan yaitu adanya pemantauan direksi pada anggaran dengan melakukan persetujuan khususnya untuk pembelian yang tidak dianggarkan sebelumnya.

Pada sub proses penerimaan barang, Unit A selama ini belum melakukan evaluasi berjalan terkait dengan sub proses penerimaan barang. Berdasarkan keterangan dari petugas gudang penerimaan barang dilakukan langsung oleh petugas gudang dan belum melibatkan staf logistik/manajer logistik. Penerimaan barang juga melibatkan bantuan dari karyawan koperasi Yayasan X. Usulan dalam komponen pemantauan yaitu, peneliti menyarankan agar Manajer Logistik secara teratur dapat memantau kegiatan penerimaan barang digudang. Kegiatan penerimaan barang penting dilakukan untuk memastikan bahwa barang yang diterima perusahaan merupakan barang yang sebenarnya dipesan oleh perusahaan (Romney dan Steinbart, 2015).Maguire (2014) menyatakan bahwa komponen pemantauan berjalan baik jika perusahaan mampu mengevaluasi dokumen-dokumen penting terkait sistem pengendalian perusahaan.Maguire (2014) juga menyatakan bahwa manajer harus memantau aktivitas dari karyawan untuk memastikan sistem pengendalian internal berjalan dengan baik.

Unit A secara umum telah menerapkan prinsip kedua komponen pemantauan pada sistem pengendalian internalnya. Secara umum manajer akan secara langsung mengoreksi kesalahan dari pelaksana/staf departemen terkait. Kesalahan yang terjadi pada proses pengeluaran pada umumnya yaitu kesalahan pencatatan kode akun saat melakukan penjurnalan. Selain itu Manajer 
Logistik pada umumnya mengoreksi kesalahan staffnya saat pembuatan purchase order secara langsung. Implementasi dari komponen pemantauan terbukti dari adanya audit yang dilaksanakan oleh SPI. SPI selalu mengaudit area keuangan termasuk berhubungan dengan siklus pengeluaran.Penelitian terdahulu dilakukan oleh Oppong et al. (2016) pada organisasi non-profit.Oppong et al. (2016) menemukan bahwa rekonsiliasi bank pada objek penelitian telah merepresentasikan pemantauan yang baik.Pemantauan yang baik tercermin dari pemisahan tugas yang tepat. Manajer harus melakukan pemantauan dengan cara memeriksa pekerjaan rekonsiliasi bank yang dilakukan oleh staff.

\section{SIMPULAN}

Tujuan penelitian adalah untuk menganalisis sistem pengendalian internal atas siklus pengeluaran pada Unit A. Penelitian ini dilakukan atas dasar temuan LHP SPI Yayasan X periode 2014 sampai 2016. Atas dasar tersebut penelitian ini difokuskan untuk memberikan usulan perbaikan bagi Unit A agar sistem pengendalian internal pada siklus pengeluaran lebih optimal.Hasil dari analisis pada komponen informasi dan komunikasi menunjukkan bahwa belum ada informasi mengenai standar kelengkapan dokumen pendukung transaksi pengeluaran.
Hasil dari analisis pada komponen pemantauan menunjukkan Manajer Logistik belum melakukan pemantauan atas proses penerimaan barang. Manajer keuangan juga belum optimal dalam melakukan pengecekan kelengkapan dari dokumen pendukung pengeluaran.

\section{REFERENSI}

Astuti, S., Zuhrotun, \& Kusharyanti. (2015) Fraudulent Financial Reporting in Public Companies in Indonesia: An Analysis of Fraud Triangle and Responsibilities of Fraud Triangle and Responsibilities of Auditors. Journal of Economics, Business, and Accountancy Ventura, 18 (1), 283-290.

Committee of Sponsoring Organizations of the Treadway Commission. (2013). Internal Control Integrated Framework and Appendices.

Giriunas, L. (2009). Evaluation of Condition of Internal Control System in the Company.Vilnius University. Ekonomika ir Vadyba: Aktualijos ir Perspektyvos, page 103-113.

Ghozali, I., \& Achmad, T. (2018). A Pilot Study of Corporate Governance and Accounting Fraud: The Fraud Diamond Model. Journal of Business and Retail Management Research, 12 (2), 253-261. 
387 AGREGAT: Jurnal Ekonomi dan Bisnis

Vol. 2, No. 2, September 2018

http://journal.uhamka.ac.id/index.php/agregat

p-ISSN: 2580-3360 e-ISSN: 2581-2874

DOI: 10.22236/agregat_vol1/is4pp377-387

Hal 377-387

Huang, S., Y., Lin, C., Chiu, A., \& Yen, D., C. (2016).Fraud Detection Using Fraud Triangle Risk Factors.Springer Science Business Media New York.

Husmawati, P., Septriani, Y., Rosita, I., \& Handayani, D. (2017).Fraud Pentagon Analysis in Assessing the Likelihood of Fraudulent Financial Statement.International Conference of Applied Science on Engineering, Business, Linguistics, and Information Technology, 46-51.

Lansiluoto, A., Jokipii, A., \& Eklund, T. (2016).Internal Control Effectiveness a Clustering Approach.Managerial Auditing Journal Vol. 31.

Lokanan, M., E. (2014). How Senior Manager Perpetuate Accounting Fraud? Lessons for Fraud Examiner from an Instructional Case.Journal of Financial Crime, 21(4), 411-423.

Maguire, K., A. (2014). Best Practices for Nonprofits Internal Control Self Assessment.Advances in Management \& Applied Economic, 4(1).

Oppong, M., Owiredu, A., Abedana, V., N., \& Asante, E. (2016).The Impact of Internal Control on the Performance of Faith-Based NGOs in Accra.Research Journal of Finance and Accounting, 7(12), 110-125.
Romney, M., B., \& Steinbart, P., J. (2015).Accounting Information Systems. London: Pearson.

Said, J., Alam, M.M., Ramli, M., dan Rafidi, M. (2017). Integrating Ethical Values into Fraud Triangle Theory in Assessing Employee Fraud: Evidence from Malaysian Banking Industry.Journal of International Studies, 10(2), 170-184.

Sugiyono. (2011). Metode Penelitian Kuantitatif Kualitatif dan R\&D. Bandung: Alfabeta.

Wahyuni, S. (2012).Qualitative Research Method Theory and Practices. Jakarta: Salemba Empat.

Zakaria, K., M., Nawawi, A., \& Salin, A. (2016).Internal Controls and Fraud Empirical Evidence from Oil \& Gas Company.Journal of Financial Crime, 23, 1-17. 
